\title{
Rapid flow assessment of congenital heart disease using high spatio-temporal gated spiral phase-contrast MR
}

\author{
Jennifer A Steeden ${ }^{1 *}$, David Atkinson ${ }^{1}$, Andrew M Taylor $^{2}$, Vivek Muthurangu ${ }^{2}$ \\ From 2011 SCMR/Euro CMR Joint Scientific Sessions \\ Nice, France. 3-6 February 2011
}

\section{Purpose}

Many sick adults and children are unable to perform long breath-holds required for conventional, Cartesian phase-contrast (PC) sequences. Using a prospectivelytriggered spiral PCMR sequence accelerated with sensitivity encoding (SENSE), it should be possible to achieve high resolution PCMR data in a short breath-hold.

The aim of this study was to compare flow volumes measured using: a) reference free-breathing, gated Cartesian PCMR, b) standard breath-hold, gated, Cartesian PCMR, and c) gated, spiral, SENSE, breath-hold PCMR.

\section{Methods}

40 consecutive children and adults were enrolled in this study (M:22, F:18, age:21.4 \pm 13.8 years). Flow was measured in the:

- Ascending aorta (AAO, N=40)

- Main pulmonary artery (MPA, N=38)

- Right pulmonary artery (RPA, $\mathrm{N}=22$ )

- Left pulmonary artery (LPA, $\mathrm{N}=24)$

Flow assessment was performed in each vessel using the three sequences above (parameters shown in Table 1).

Stroke volume and regurgitation fraction were calculated for each patient. Additionally, $\mathrm{Qp} / \mathrm{Qs}(\mathrm{N}=38)$ and RPA/LPA $(\mathrm{N}=20)$ ratios were quantified where possible.

\section{Results}

Average scan time was $91 \pm 17$ seconds for the reference free-breathing sequence, $16 \pm 3$ seconds for the standard breath-hold sequence, and $5 \pm 1$ seconds for the spiral breath-hold sequence.

'University College London, London, UK

Full list of author information is available at the end of the article

Combining all vessels $(\mathrm{N}=124)$, there were no statistical differences in mean stroke volume calculated from the reference free-breathing sequence $(60.3 \pm 27.3 \mathrm{~mL})$, the standard breath-hold sequence $(59.8 \pm 27.6 \mathrm{~mL})$ and the spiral breath-hold sequence $(59.5 \pm 27.1 \mathrm{~mL})$. BlandAltman analyses are shown in Figure 1. There was no clinically significant bias using either breath-hold sequence (spiral breath-hold: $-0.7 \mathrm{~mL}$, standard breathhold: $-0.5 \mathrm{~mL}$ ). However, the limits of agreement were smaller and the correlation better for the spiral breath-

Table 1

\begin{tabular}{llll}
\hline & $\begin{array}{l}\text { Free- } \\
\text { Breathing } \\
\text { PCMR }\end{array}$ & $\begin{array}{l}\text { Standard Breath- } \\
\text { hold PCMR }\end{array}$ & $\begin{array}{l}\text { Spiral Breath- } \\
\text { hold PCMR }\end{array}$ \\
\hline $\begin{array}{l}\text { TE/TR (ms) } \\
\text { Spiral Readouts }\end{array}$ & $\sim 2.2 / 7.0$ & $\sim 2.2 / 7.0$ & $2.1 / 8.0$ \\
$\begin{array}{l}\text { Acceleration } \\
\text { factor }\end{array}$ & 2 (GRAPPA) & 2 (GRAPPA) & 36 \\
$\begin{array}{l}\text { Matrix Size } \\
\text { FOV (mm) }\end{array}$ & $256 \times 192$ & $192 \times 113$ & $256 \times 256$ \\
$\begin{array}{l}\text { Rectangular FOV } \\
\text { (\%) }\end{array}$ & 75 & $290-400$ & 400 \\
$\begin{array}{l}\text { Readouts per } \\
\text { segment }\end{array}$ & 3 & 66 & 100 \\
$\begin{array}{l}\text { Pixel bandwidth } \\
\text { (Hz/pixel) }\end{array}$ & 543 & 4 & 2 \\
$\begin{array}{l}\text { VENC (cm/s) } \\
\text { NSAs }\end{array}$ & $180-400$ & $180-400$ & $180-400$ \\
$\begin{array}{l}\text { Gating } \\
\text { Total Scan }\end{array}$ & 3 & 1 & 1 \\
$\begin{array}{l}\text { Duration (s) } \\
\text { Voxel Size (mm) }\end{array}$ & $\sim 0.8-1.5$ & $\sim 1.5-2.1$ & 1.6 \\
$\begin{array}{l}\text { Remporal } \\
\text { resolution }\end{array}$ & $\sim 30.0 \mathrm{~ms}$ & $\sim 40.0 \mathrm{~ms}$ & $32.0 \mathrm{~ms}$ \\
\hline & & & $3-8$ \\
\hline
\end{tabular}



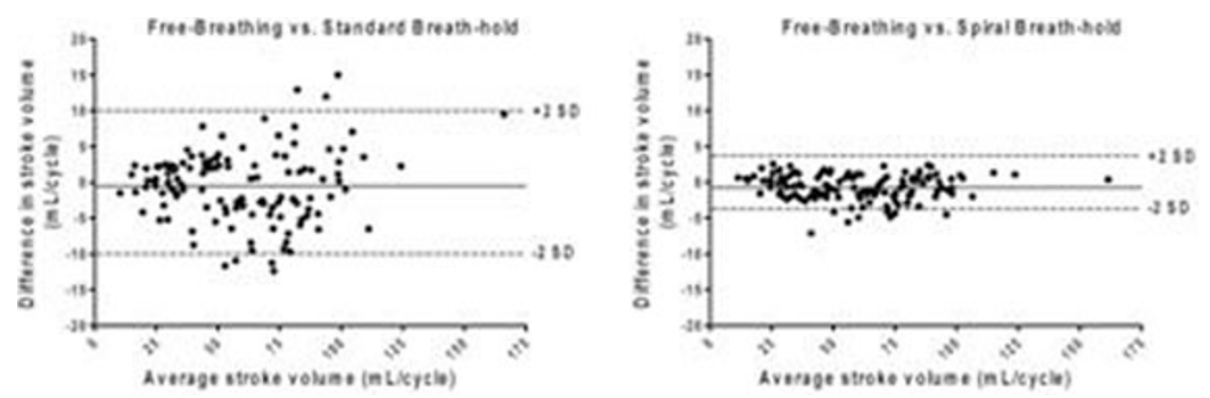

Figure 1

hold compared to the standard breath-hold sequence ( -4.4 to $2.9 \mathrm{~mL}$ vs. -10.3 to $9.3 \mathrm{~mL}$, respectively).

There was also an excellent agreement in QP/QS and RPA/LPA ratios between all sequences, however the spiral breath-hold sequence was found to be superior to the standard breath-hold sequence in terms of limits of agreement and correlation. There was a small but statistically significant underestimation of regurgitation fraction using the spiral sequence.

\section{Conclusion}

Flow volumes can be accurately and reliably quantified using a spiral SENSE PCMR sequence, with high spatiotemporal resolution in a short breath-hold. As the standard method of measuring flow in congenital heart disease is free-breathing, cardiac gated PCMR, this spiral sequence could reduce total flow imaging from $\sim 10$ minutes, to $<1$ minute. This is a marked reduction in total scan time and has implications for patient throughput and compliance for congenital cardiac MR scanning.

\section{Author details}

${ }^{1}$ University College London, London, UK. ${ }^{2}$ UCL, Institute of Child Health, London, UK.

Published: 2 February 2011 